\title{
Renal artery stenosis due to abdominal aortic aneurysm
}

\author{
M. N. LOWENTHAL \\ M.B., Ch.B.(W'srand), M.R.C.P.E. \\ Physician Specialist
}

General Hospital, Ndola

S. A. Doctor

M.B., B.S.(Osmania), F.R.C.S.E.

Surgical Specialist

\author{
J. FINE \\ M.D.(Glas.) D.P.H. \\ Pathologist, Central Hospital, Kitwe, \\ Ministry of Health, Republic of Zambia
}

THE NUMEROUS causes of renal artery stenosis have been reviewed by de Camp \& Birchall (1958). In their review they cited only one case of renal artery stenosis due to an aortic aneurysm (Hoffman, 1942). Since then there have been reports of three more such cases (Brown et al., 1960; Abrahams \& Parry, 1962). In this paper we report a further case.

\section{Case report}

First admission. The patient was a 37-year-old Zambian African male schoolteacher admitted in July 1965 for the investigation of left lumbar pain. He stated that in 1947 he had passed blood in the urine and was treated for schistosomiasis.

Investigations included cystoscopy which revealed 'a tight left ureteric orifice and a few bilharzial tubercles'. The patient was treated with an antimonial and sulphadimidine.

Second admission. This took place on 10 December 1965 with the patient complaining of episodes of bilateral loin pain radiating to the front, followed by sweating, vomiting and severe frontal headache.

Physical examination revealed an ill-looking, thin, anxious man. Temperature $98^{\circ} \mathrm{F}$; BP between $190 / 140$ and $190 / 160 \mathrm{mmHg}$. pulse rate $100 \mathrm{~min}$. No abnormalities were detected in the heart, chest or abdomen. The fundi were normal. Renal angle tenderness was not elicited. Auscultation to determine the presence of a renal arterial bruit was not carried out.

Investigations. The 24-hr urinary output varied between 1.5 and 1.62 litres. Urinary specific gravity, 1018. There was a + test for protein, the sediment showed a few pus cells, and on

Requests for reprints to Dr M. N. Lowenthal, P.O. Box 166, Ndola, Zambia. culture B. coli were grown. $\mathrm{Hb} 13.2 \mathrm{~g} / 100 \mathrm{ml}$, ESR $75 \mathrm{~mm} / \mathrm{hr}$, WBC $9000 / \mathrm{mm}^{3}$, polymorphonuclears $89 \%$, lymphocytes $11 \%$. The direct test for sickling was positive.

Blood urea $20 \mathrm{mg} / 100 \mathrm{ml}$. A phentolamine test was negative. Blood Kahn test was negative.

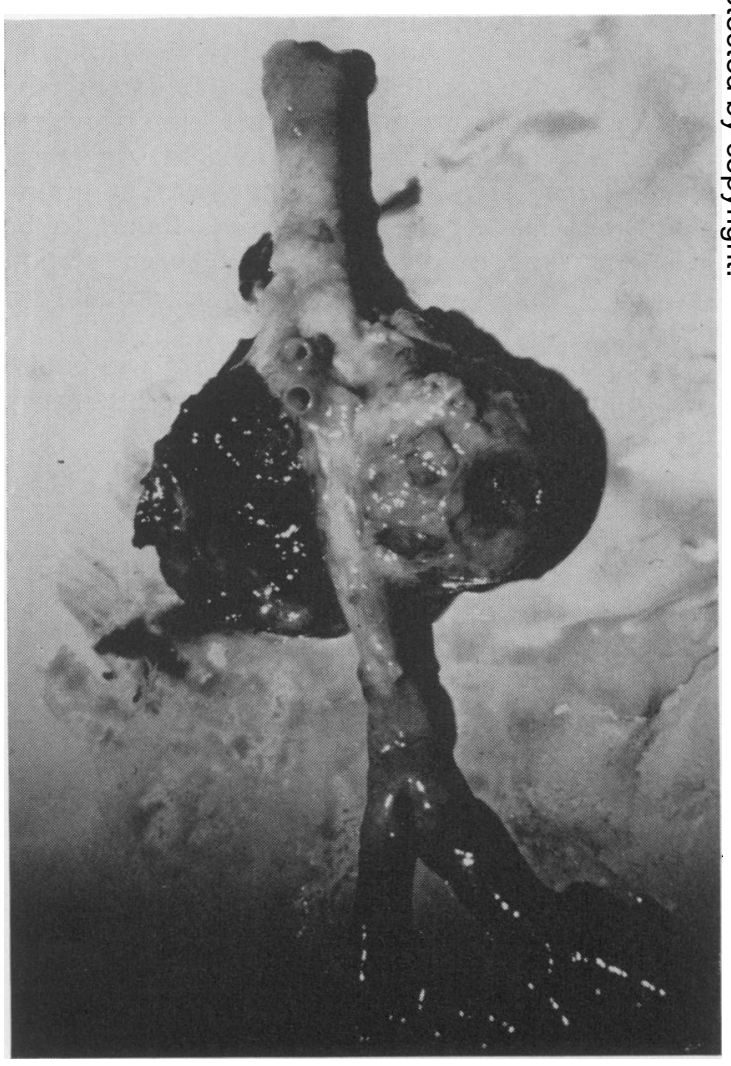

Fig. 1. Abdominal aortic aneurysm. 


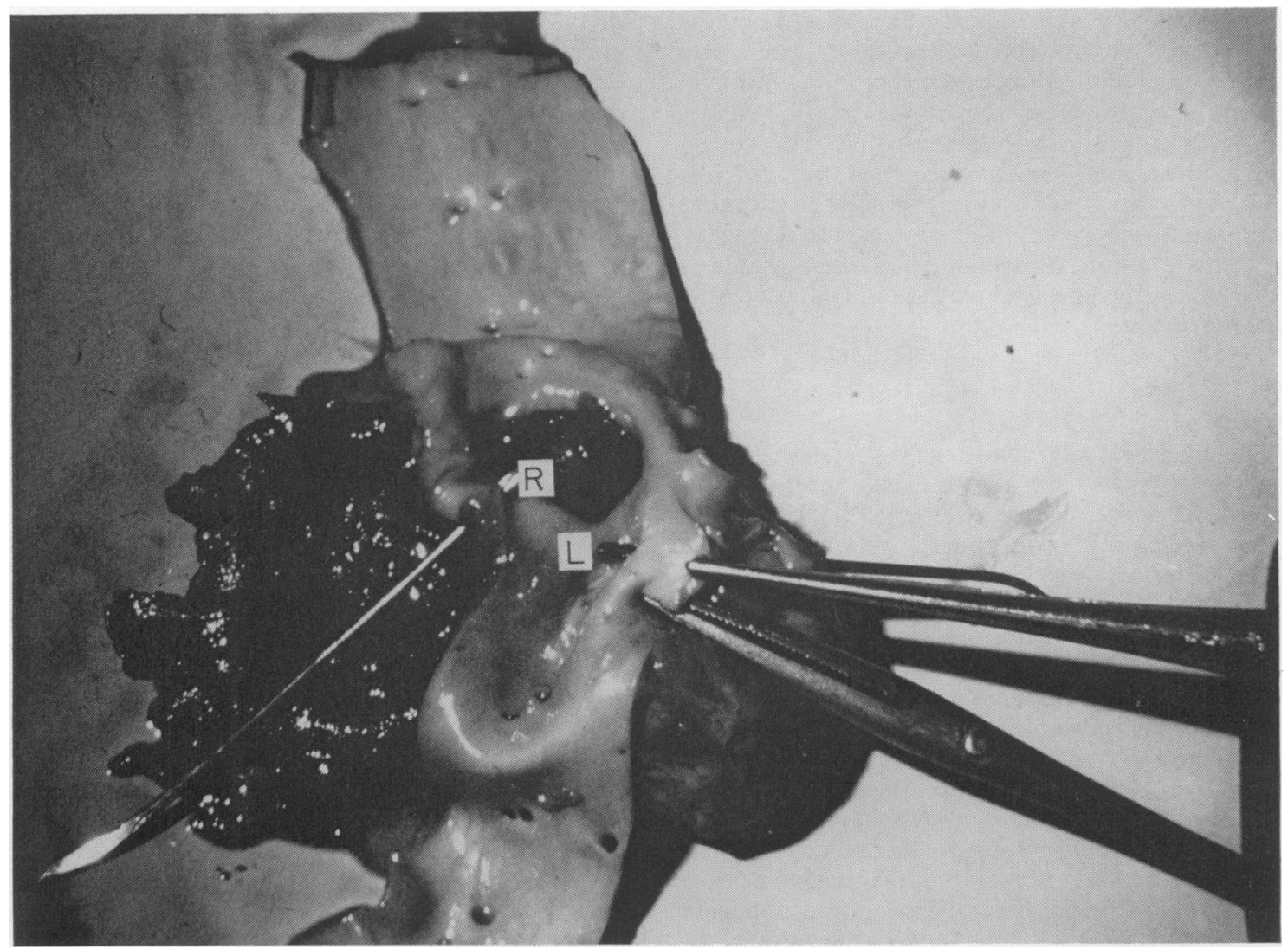

FIG. 2. Interior view of aneurysm. $\mathbf{R}$, Probe in right renal artery; L, probe in left renal artery.

Plain X-rays of chest and abdomen were normal.

Intravenous pyelogram showed normal structure and function of the left kidney but complete failure of excretion or visualization of the right kidney.

Cystoscopy revealed mild trabeculation of the bladder wall, a lustreless mucosa compatible with healed schistosomiasis but no evidence of active infection, and a mild anterior urethral stricture. The right ureteric orifice was narrowed. Retrograde pyelography revealed an abnormally small right renal pelvis with approximation of the calyces. Therapy with methyldopa $250 \mathrm{mg}$ t.i.d. was commenced on the 4th day after admission, and on the 6th day the dose was increased to $500 \mathrm{mg}$ t.i.d.

At this stage the clinical diagnosis was hypertension due to unilateral right pyelonephritis secondary to vesical schistosomiasis. On the 28th hospital day right nephrectomy was performed. Shortly before final mobilization of the kidney, cardiac arrest occurred. Open cardiac massage restored normal heart action, but the patient never fully regained consciousness and died 11 days post-operatively.

The right kidney appeared macroscopically normal except for its small size; length $8 \mathrm{~cm}$ weight $70 \mathrm{~g}$. On section the cortex showed areas of pallor and areas of congestion. Microscopically there was marked congestion of the glomerular tufts and of the small medullary vessels.

Necropsy was performed $31 \frac{1}{2} \mathrm{hr}$ after death. The left kidney was normal except for slight congestion of the cortex and medulla. Ureters and bladder were normal.

The aorta overlying the first and second lumbar vertebrae was dilated to form a saccular aneurysm approximately $3 \frac{1}{2}$ in. $(8.9 \mathrm{~cm})$ in transverse diameter (Fig. 1). Below the aneurysm the diameter of the aorta was reduced to approximately half. The coeliac and superior mesenteric arteries arose from the upper part of the aneurysm. The lateral and anterior extensions of the aneurysm enveloped both renal arteries causing marked stenosis of the right and some 
stenosis of the left (Fig. 2). Most of the aneurysmal sac contained blood clot. The aorta was free of atheroma except for a minimal amount immediately above the aortic valves. The left ventricle was hypertrophied. The coronary arteries and valves were healthy. Microscopy of the aortic aneurysm revealed a fibrinous thrombus overlying a thinned degenerate media, the muscle fibres of which were destroyed and replaced by hyaline fibrous tissue. The adventitia was normal.

\section{Discussion}

The diagnosis of renal artery stenosis was not considered prior to post-mortem examination. Unilateral renal disease was the working diagnosis seemingly confirmed by pyelography. Renal arteriography, a procedure not available at this hospital, was not thought to be necessary.

The Nigerian patient described by Abrahams \& Parry (1962) as having renal artery stenosis caused by an abdominal aortic aneurysm presented with a pulsatile swelling in the abdomen. Nephrectomy was successfully performed in this case, so material from the aneurysm was not available for examination. Abrahams \& Parry (1962) considered syphilis to have been successfully excluded as a possible diagnosis in their case, as we do in ours. These authors believe that their case falls into either the group described by Abrahams \& Cockshott (1962) as multiple non-luetic aneurysms of the great vessels of uncertain aetiology, or the group having idiopathic aortitis with lesions similar to the pulseless disease-giant cell aortitis complex described by Isaacson (1961).

The histological features in our case to some extent resemble those described by Abrahams \& Cockshott (1962) in the one case in their series in which microscopy was possible. Thus we believe that the case we describe probably falls into this group. Two other cases resembling the ones described by Abrahams \& Cockshott (1962) have been seen here in the last 2 years; one a female child with a pulsatile swelling in the neck, and the other a middle-aged man with multiple aneurysms of the ascending, arch and descending parts of the aorta not due to syphilis.

\section{Acknowledgments}

We are grateful to Mr Donald M. McNab, F.R.C.S.E., for his assistance in this case, and to Mr Ralph Krag-Olsen for photographic reproductions.

The Permanent Secretary, Ministry of Health, kindly gave permission to publish.

\section{References}

Abrahams, D.G. \& CockshotT, W.P. (1962) Multiple nonluetic aneurysm in young Nigerians. Brit. Heart J. 24, 83.

Abrahams, D.G. \& Parry, E.H.O. (1962) Hypertension due to renal artery stenosis caused by abdominal aortic aneurysm. Circulation, 26, 104.

Brown, J.J., OWen, K., Peart, W.S., Robertson, J.I.S. \& Sutron, D. (1960) The diagnosis and treatment of renal artery stenosis. Brit. med. J. ii, 327.

DE CAMP, P.T. \& Birchall, R. (1958) Recognition and treatment of renal arterial stenosis associated with hypertension. Surgery, 43, 134.

HofFMAN, B.J. (1942) Renal ischaemia produced by aneurysm of abdominal aorta, J. Amer. med. Ass. 120, 1028.

IsAACSON, C. (1961) An idiopathic aortitis in young Africans. J. Path. Bact. 81, 69. 